\title{
A New Frontier Drug Development in Nanomedicine and Its Anti-urolithiatic Activity of Kalanchoe pinnata
}

\author{
F. JANEETA PRIYA ${ }^{1 *}$, A. LEEMAROSE ${ }^{2}$, S. VIDHYA ${ }^{3}$, A. ARPUTHARAJ ${ }^{4}$, \\ S. AKSHANA ${ }^{5}$ and U. F. RAMEEZ FATHIMA ${ }^{6}$ \\ 1,2,3,5,6, PG and Research Department of Chemistry,Holy Cross College, Affiliated to Bharathidasan \\ University, Tiruchirappalli-6200 02, Tamil Nadu, India. \\ ${ }^{4}$ Department of Electronics, St. Joseph's College, Affiliated to Bharathidasan University, \\ Tiruchirappalli-6200 02, Tamil Nadu, India. \\ *Corresponding author E-mail: janeetapriya@gmail.com
}

http://dx.doi.org/10.13005/ojc/370226

(Received: February 16, 2021; Accepted: March 26, 2021)

\section{ABSTRACT}

\begin{abstract}
Latterly, the green synthesis of metallic nanoparticles has stock pile and terminal interest over the last decade due to their idiosyncratic properties that make them felicitous in various fields of science and technology. In this study the silver nanoparticles can be manufacture by using the leaf extract of Kalanchoe pinnata plant using microwave radiation method. The nanoparticles that are synthesized by plants are non-toxic and eco-friendly and it is characterized by using UV-Visible, FT-IR , X-ray diffraction (XRD) and TEM. The crystalline natures of the synthesized silver nanoparticles were identified by XRD and its shape was confirmed by TEM analysis. Anti-urolithiatic activity of synthesized silver nanoparticles was accomplished which reduces the growth of kidney stone which was appraisal by using the In vitro growth of urinary calculi.
\end{abstract}

Keywords: Kalanchoe pinnata, UV-Vis, FTIR, TEM, XRD, Anti-urolithiatic activity.

\section{INTRODUCTION}

Kidney stone is a most common disease for urinary tract infections. It is the type of disorder which affects the $12 \%$ of the population in the world ${ }^{1-3}$. At the end stage it leads to the renal failure. The contraption of the stone formation involves the complex process such as nucleation, super saturation, growth, aggregation and retention process which are associated with the physiochemical events. Contemporarily, there is no adequate drug to cure the prevention of reoccurrences of kidney stone. Recent studies investigated the work on the silver nanoparticles which are incorporated with the plant extract shows the medicinal applications and especially the anti-urolithiatic activity. The leaves of the Kalanchoe pinnata plant naturally containing the various anti-oxidant properties. The leaf powder of this plant was taken for curing the burning in urination, blocked urination and leprosy ${ }^{4}$. The compounds present in the plants can acts as anticancer agents. Kalanchoe pinnata is far better than aspirin; the aqueous extract of this plant shows the antinoceptive effect and produces the hormone such as prostaglandin, histamine. Currently, organic and inorganic nanoparticles can attractively to the

This is an Open Access article licensed under a Creative Commons license: Attribution 4.0 International (CC- BY). Published by Oriental Scientific Publishing Company @ 2018

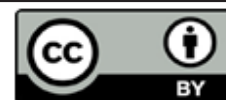


field for diagnosis of kidney stones ${ }^{5-7}$. The silver nanoparticles were synthesized from the aqueous solution of silver nitrate by using the leaf extract of Kalanchoe pinnata plant ${ }^{8}$.

\section{EXPERIMENTAL}

\section{Collection of plant materials}

The healing plant used in this study is the leaves of Kalanchoe pinnata plant which was collected from the Gandhi market area of Tiruchirappalli district, Tamil Nadu. The collected leaves were thoroughly washed with running water and shade dried for 10-15 days after that with the help of mortar and pestle the leaves were grinded; the powdered plant sample is utilized for the synthesis of silver nanoparticles.

\section{Preparation of the extract}

The Kalanchoe pinnata plant leaf extract was prepared by using water as a solvent. By using solvent extraction process the plant extract was prepared. Then hot percolation method was carried out and the filtrate can be collected and it might be used for further studies ${ }^{9}$.

\section{Quantitative analysis of Kalanchoe pinnata leaf} To find out the quantity of the major phyto constituents like flavanoids, tannin, saponin, alkaloid, phenol and terpinoids were present carried out by using stranded procedure.

\section{Synthesis of silver nanoparticle}

First an aqueous solution $5 \mathrm{Mm}$ of silver nitrate is prepared using water as solvent and it is taken in a beaker and then $1 \mathrm{~mL}$ of leaf extract was added to required amount of $\mathrm{AgNO}_{3}$ solution. After half an hour the colour changes from colour less to dark brown, which indicates the formation of AgNPs. The colloidal solution was taken for further analysis.

\section{Characterization of silver nanoparticles UV-visible analysis}

The synthesized silver nanoparticles were carried out with the UV-Visible spectrophotometer from the range of $300-800 \mathrm{~nm}$. The band can be obtained in the colloidal silver nanoparticles is $400-450 \mathrm{~nm}$ due to the excitation of surface plasma vibration.

\section{FT-IR analysis}

FT-IR measurements are used to identify the functional groups present in the plant extract and also used to find out the stability of the silver nanoparticles. The specific functional groups present in their corresponding frequency were observed.

\section{XRD}

This measurement is used to affirm the crystalline nature of silver nanoparticles ${ }^{11}$. From this also measure the purity of the substance. According to (JCPDS, File n04-0783) the swatch shows the face centered cubic structure for silver.

\section{TEM}

This analysis is used to measure the dimensions, structure and exterior morphology were identified with the help of this technique. In this technique, image can be formed with the help of interaction of electrons transmitted through the specimen.

\section{In vitro growth of urinary calculi Growth of CHPD crystals}

About $1 \mathrm{M}$ solution of $\mathrm{H}_{3} \mathrm{PO}_{4}$ was mixed with $\mathrm{Na}_{2} \mathrm{SiO}_{3}$ solution of density $1.04 \mathrm{~g} / \mathrm{cm}^{3}$ at $\mathrm{pH}$ 9.4 and it was left aside for 2-3 days so that the $\mathrm{pH}$ of the solutions was maintained. After gelatin formation process, the liquid shows above a solid residue of $1 \mathrm{M}$ solution of $\mathrm{CaCl}_{2}$ was poured onto the set gel in different glass test tubes, and then it was stopper with airtight stopples. The experiments were maintained at room temperature $\left(37^{\circ} \mathrm{C}\right)$.

To examine the hypothetical activity of the extract as inhibitors of CHPD crystal development in gel technology. To find out the efficiency of leaf of Kalanchoe pinnata on the growth of CHPD Crystals, various concentrations of synthesized silver nanoparticles are added. After thirty days the development of crystals are analyzed and calculated $^{12-15}$.

\section{RESULTS AND DISCUSSION}

\section{Quantitative analysis}

This analysis revealed the amount of phytochemical constituents present in the aqueous extract of Kalanchoe pinnata leaves. The various quantities of phytochemical present in the extract were shown in Table 1.

Table 1: Quantitative analysis of Kalanchoe pinnata leaves

\begin{tabular}{ccc}
\hline S. No & Phytochemical constituents & Kalanchoe pinnata $(\mathrm{mg} / \mathrm{g})$ \\
\hline 1 & Alkaloids & 0.007 \\
2 & Saponin & 0.006 \\
3 & Flavanoid & 0.012 \\
4 & Phenol & 0.01 \\
5 & Tannin & 0.005 \\
6 & Terpenoids & 0.005 \\
\hline
\end{tabular}




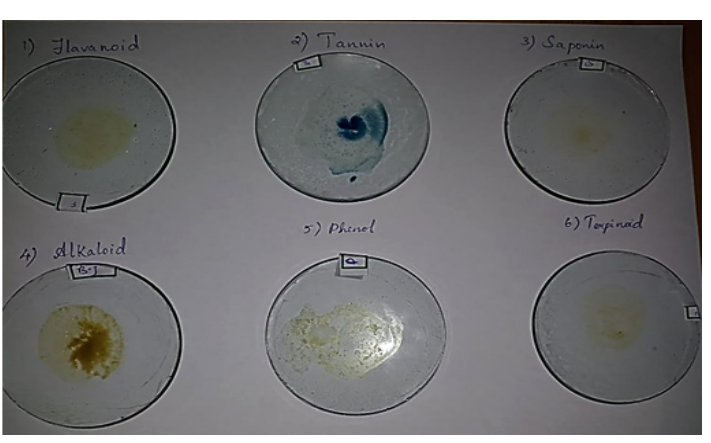

Fig. 1. Visual observation of phytochemical constituent present in Kalanchoe pinnata

Federico used HPLC-ESI/MS method to derive the phenolic compounds from the leaves of Kalanchoe pinnata and then leaves of Kalanchoe pinnata contain high level of flavonoids. Flavonoids used to prevent the oxidative cell damage, have strong anti-cancer activity. It contains high concentration of flavonoids followed by alkaloids, glycosides and steroids have been reported to be present in the aqueous leaf extracts (Figure 1).

\section{Visual observation}

In this experimental method, the addition of $50 \mu \mathrm{l}$ aqueous extract of Kalanchoe pinnata is taken in a glass vial to that $1 \mathrm{ml}$ of $5 \mathrm{mM} \mathrm{AgNO}_{3}$ solution is added drop by drop after $2 \mathrm{~h}$ the colour of the solution slightly changes from colorless to brown as shown in Fig. 2. The solution is centrifuged using cooling centrifuge at $15000 \mathrm{rpm}$ then it is stored in the refrigerator for further analysis.
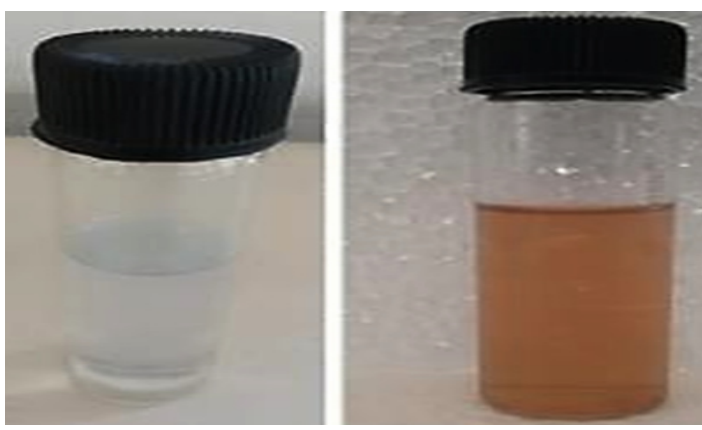

Fig. 2 (a) Silver nitrate solution, (b) synthesized silver nanoparticles

\section{Characterization techniques UV-visible spectroscopy}

To determine the optical properties of a solution, absorbance spectroscopy is used. The broad absorption peak of synthesized silver nanoparicles was observed at $439 \mathrm{~nm}$ was shown in Fig. 3 . The phytochemical constituent present in Kalanchoe pinnata leaves extract was responsible for the reduction of silver nitrate to silver nanoparticles.

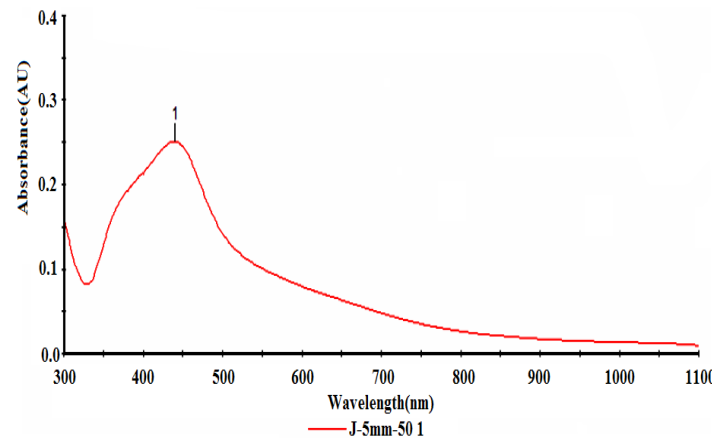

Fig. 3. UV-Vis spectrum of synthesized silver nanoparticles

\section{FT-IR analysis}

FT-IR measurements are taken to identify the functional group involved in this process. The FT-IR Spectra of synthesized silver nanoparticles were shown in Fig. 4. The corresponding peaks observed in the synthesized silver Nanoparticles are shown in the Table 2.

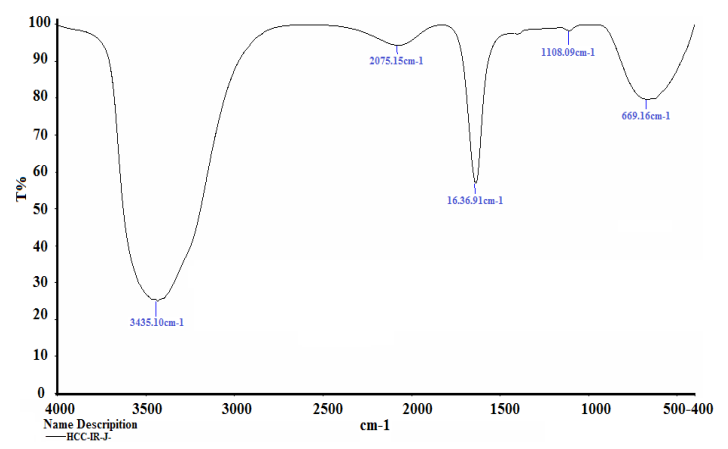

Fig. 4. FT-IR spectral data of synthesized AgNPs

Table 2; FT-IR spectral data of synthesized silver nanoparticles

\begin{tabular}{|c|c|c|}
\hline Functional group & Band & Frequency, $\mathrm{cm}^{-1}$ \\
\hline Primary amine & medium band & $\begin{array}{l}3435 \mathrm{~cm}^{-1} \text { corresponds to } \\
\mathrm{N}-\mathrm{H} \text { stretching vibrations }\end{array}$ \\
\hline Isothiocyanate & strong band & $\begin{array}{l}2075 \mathrm{~cm}^{-1} \text { corresponds to } \\
\mathrm{N}=\mathrm{C}=\mathrm{S} \text { stretching vibrations }\end{array}$ \\
\hline Alkene & medium band & $\begin{array}{l}1636 \mathrm{~cm}^{-1} \text { corresponds to } \\
\mathrm{C}=\mathrm{C} \text { stretching vibrations }\end{array}$ \\
\hline Amine & medium band & $\begin{array}{l}1108 \mathrm{~cm}^{-1} \text { corresponds to } \\
\mathrm{C}-\mathrm{N} \text { stretching vibrations }\end{array}$ \\
\hline Halo compound & strong band & $\begin{array}{l}669 \mathrm{~cm}^{-1} \text { corresponds to } \\
\mathrm{C}-\mathrm{Br} \text { stretching vibrations }\end{array}$ \\
\hline
\end{tabular}

\section{Transmission electron microscope}

This study is used to identify dimensions, structure and exterior morphology of the synthesized nanoparticles. From this analysis, the synthesized AgNPs are well scattered and mostly spherical and some are having the structures of irregular in shape as shown in Fig. 5. The synthesized nanoparticles are homogeneous and spherical having 200nm and $100 \mathrm{~nm}$ range. 


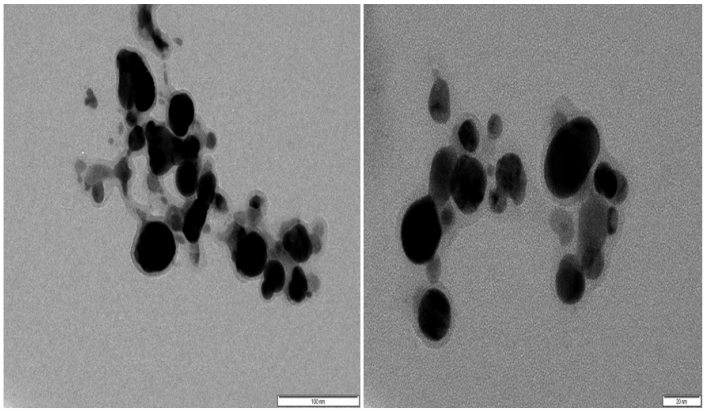

Fig. 5. TEM image of synthesized silver nanoparticle using Kalanchoe pinnata
XRD spectrum of silver nanoparticles

$X$-Ray Diffraction analysis used to find out the crystalline character of AgNPs. The analysis and XRD data are given in Table 3. Fig. 6 represents $\mathrm{XRD}$ analysis of synthesized silver nanoparticle using Kalanchoe pinnata. The peak corresponds at $38.4024,44.8685$ following diffraction faces are (111), (200) respectively. Unassigned peaks are as present in the graph this may due to extract contains some phytochemicals which may be capping the surface of nanoparticles.

Table 3: XRD analysis of synthesized silver nanoparticle using Kalanchoe pinnata

\begin{tabular}{|c|c|c|c|c|}
\hline Position [ ${ }^{\circ}$ Th.] & Heights[cts] & FWHM degree ${ }^{\circ} 2$ Theta & d-spacing $[\AA ̊]$ & Rel. Int. [\%] \\
\hline 17.1629 & 28.03 & 0.1476 & 5.16660 & 8.20 \\
\hline 27.9614 & 170.73 & 0.2460 & 3.19103 & 49.92 \\
\hline 32.3356 & 341.99 & 0.2460 & 2.76866 & 100.00 \\
\hline 38.4024 & 28.41 & 0.5904 & 2.34408 & 8.31 \\
\hline 44.8685 & 126.28 & 0.1968 & 2.02015 & 36.92 \\
\hline 46.3896 & 143.71 & 0.2460 & 1.95740 & 42.02 \\
\hline 54.9414 & 35.31 & 0.2952 & 1.67125 & 10.33 \\
\hline 57.6203 & 44.36 & 0.1476 & 1.59976 & 12.97 \\
\hline 65.1721 & 176.29 & 0.1476 & 1.43146 & 51.55 \\
\hline 76.8331 & 23.92 & 0.2952 & 1.24070 & 6.99 \\
\hline 78.2896 & 273.67 & 0.1800 & 1.22021 & 80.02 \\
\hline 78.5638 & 126.02 & 0.1200 & 1.21966 & 36.85 \\
\hline
\end{tabular}

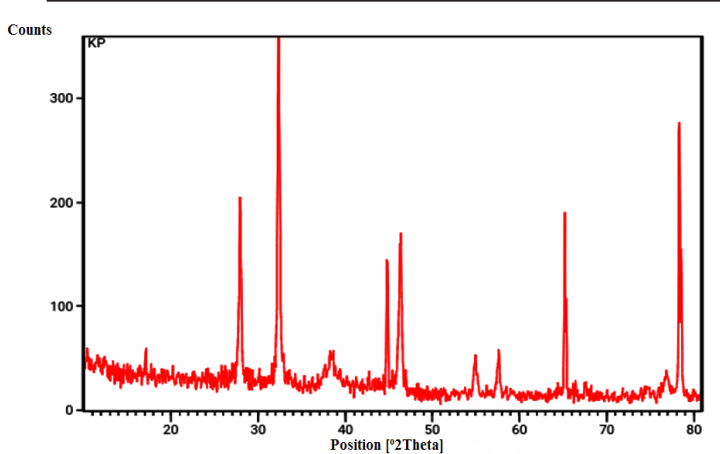

Fig. 6. XRD analysis of synthesized silver nanoparticle using Kalanchoe pinnata

\section{Effect of Kalanchoe pinnataon CHPD crystals}

The analysis of Kalanchoe pinnata extract on nucleation and crystallization of CHPD crystals is determined by finding out the quantity of crystals formed. The generations of Liesegang (5-10 rings) rings which have induce crystals growth (Fig. 7). In this technique, CHPD crystals development was reduced and framework of the crystals converted from hydroxyapatite in brushite crystals because of its inhibitory ability of nanoparticles at In vitro actions.
The formation of the control CHPD and combined with Kalanchoe pinnata CHPD crystals was shown below in Fig. 7. The amount of inhibition are shown in the Table 4.

\section{Characterization of CHPD crystals}

The Fourier transfer infra red spectral analysis of Calcium Hydrogen Phosphate dihydrate in presence and absence of the methanolic extract of sample shown below.

Table 4: inhibition of crystal growth

\begin{tabular}{lccc}
\hline Crystals & $\begin{array}{c}\text { Supernatant solution } \\
\text { (groups and treatments) }\end{array}$ & $\begin{array}{c}\text { Weight of } \\
\text { crystal }\end{array}$ & $\begin{array}{c}\text { Percentage } \\
\text { inhibition } \\
\text { of crystal }\end{array}$ \\
\hline CHPD & I & 132 & $0 \%$ \\
II & 72.6 & $45 \%$ \\
III & 51.6 & $60.9 \%$ \\
IV & 44.5 & $66.2 \%$ \\
V & 34 & $74.2 \%$ \\
VI & 26 & $80.3 \%$ \\
VII & 20 & $84.8 \%$ \\
\hline
\end{tabular}



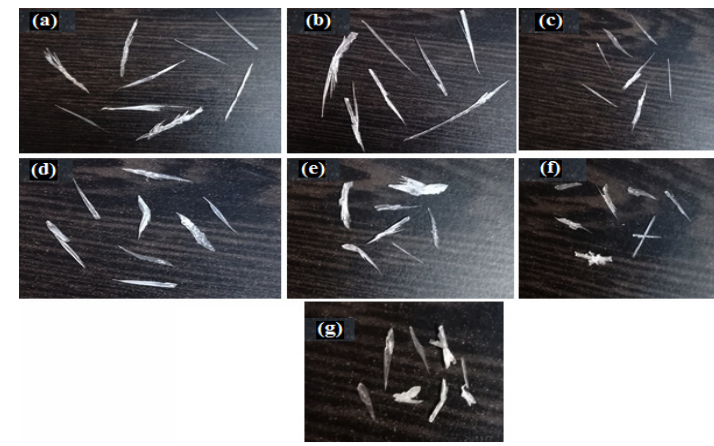

Fig. 7. The effect of leaves extract of Kalanchoe pinnata on Growth of Calcium Hydrogen Phosphate dihydrate crystals in the gel technique : Fig. 7(a) represents the Control which is taken for the analysis, Fig. 7(b) shows the distilled water taken, Fig. 7(c), 7(d), 7(e), 7(f), 7(g) represents the various concentrations $(1 \%, 2 \%, 3 \%, 4 \%$ and $5 \%)$ of aqueous extract of synthesized silver nanoparticle synthesised from the leaves of Kalanchoe pinnata

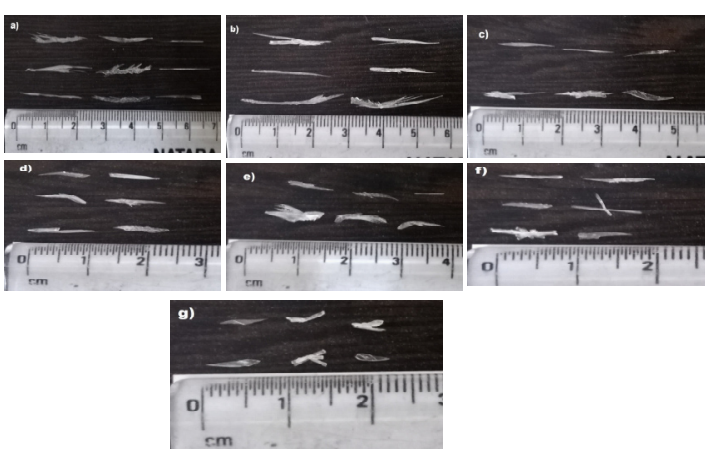

Fig. 8. Measurement of harvested Calcium Hydrogen Phosphate dihydrate crystals obtained from the leaves of Kalanchoe pinnata in the gel technique : Fig. 8(a) represents the Control which is taken for the analysis, Fig. 8(b) shows the distilled water taken, Fig. 8(c), 8(d), 8(e), 8(f), 8(g) represents the various concentrations $(1 \%, 2 \%, 3 \%, 4 \%$ and $5 \%$ ) of aqueous extract of synthesized silver nanoparticle synthesised from the leaves of Kalanchoe pinnata

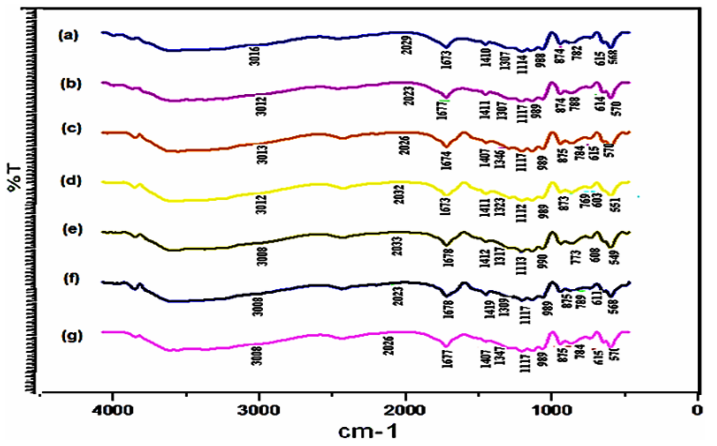

Fig. 9. The Fourier transfer infra red spectral analysis of Calcium Hydrogen Phosphate Dihydrate in the gel technique (a) without any additive (b) along the distilled water Fig.9(c), 9(d), 9(e), 9(f),9(g), represents the various concentrations $(1 \%, 2 \%, 3 \%, 4 \%$ and $5 \%)$ of aqueous extract of synthesized silver nanoparticle synthesised from the leaves of Kalanchoe pinnata
Table 5: The FTIR spectral analysis of CHPD in the gel technique

\begin{tabular}{ll}
\hline Frequencies & Band \\
\hline $3016 \mathrm{~cm}^{-1}$ & intermolecular $\mathrm{H}$ bonded $\mathrm{OH}$ \\
$2029 \mathrm{~cm}^{-1}$ & the peak is due to $\mathrm{HPO}_{4}^{2}$ \\
$1673 \mathrm{~cm}^{-1}$ & $\mathrm{H}-\mathrm{O}-\mathrm{H}$ bending \\
$1410 \mathrm{~cm}^{-1}$ & $\mathrm{P}=\mathrm{O}$ combined with stretching vibrations \\
$1114 \mathrm{~cm}^{-1}$ & $\mathrm{P}=\mathrm{O}$ stretching vibrations \\
$988,874 \mathrm{~cm}^{-1}$ & $\mathrm{P}-\mathrm{O}-\mathrm{P}$ asymmetric stretching vibrations \\
$615 \mathrm{~cm}^{-1}$ & owing to (H-O-) $\mathrm{P}=\mathrm{O}$ \\
$3012 \mathrm{~cm}^{-1}$ & intermolecular and weakly H bonded $\mathrm{OH}$ \\
$1677 \mathrm{~cm}^{-1}$ & H-O-H bending \\
$2023 \mathrm{~cm}^{-1}$ & week absorption of HPO ${ }^{2-}$ \\
$1407 \mathrm{~cm}^{-1}$ & $\mathrm{P}=\mathrm{O}$ associated stretching vibrations \\
$1117 \mathrm{~cm}^{-1}$ & $\mathrm{P}=\mathrm{O}$ stretching vibrations. \\
$874 \mathrm{~cm}^{-1}$ & P-O-P asymmetric stretching vibrations \\
$788 \mathrm{~cm}^{-1}$ & due to (H-O-)P=O \\
$578 \mathrm{~cm}^{-1}$ & strong absorption peak at acid phosphate \\
$3013 \mathrm{~cm}^{-1}$ & absorption of OH ions \\
$2026 \mathrm{~cm}^{-1}$ & PO4 stretching vibrations \\
989,875 and & P-O-P asymmetric stretching vibrations \\
$784 \mathrm{~cm}^{-1}$ & \\
$615,570 \mathrm{~cm}^{-1}$ & acid phosphate \\
$2023 \mathrm{~cm}^{-1}$ & owing to PO stretching vibrations \\
989,873 and & P-O-P asymmetric stretching vibrations \\
$769 \mathrm{~cm}^{-1}$ & \\
$603,551 \mathrm{~cm}^{-1}$ & Owing to acid phosphate. \\
\hline &
\end{tabular}

\section{CONCLUSION}

By using the green method, synthesis of therapeutically used nanoparticles should be produced which is more effective and manufactured at larger scale. There may be a lot of upgrade treatments are available to treat the kidney stone. It is one among the study to medicaments the kidney stone by using naturally available plants with the help of nanoparticles synthesis and it is proved by carrying out certain studies are discuss above. This study concluded that the synthesis of silver nanoparticles using plant extract is energy efficient and bio-hazardous chemical synthesis. Our present study is to contribute for green chemistry particularly and also the green synthesis metal of nanoparticles and analyze it's therapeutic applications.

\section{ACKNOWLEDGMENT}

This research did not receive any specific grant from funding agencies in the public, commercial, or not-for-profit sectors.

\section{Conflicts of Interest}

The authors declare no conflict of interest. 


\section{REFERENCES}

1. Phanjom, P.;Ahmed, G. Nanosci. Nanotechnol., 2015, 5(1), 14-21.https://doi.org/10.5923/j. nn.20150501.03.

2. Dixon, R.A.; Xie, D.-Y.; Sharma, S.B. New Phytol., 2005,165, 928. https://doi. org/10.1111/j.1469-8137.2004.01217.x.

3. Verkoelen, C. F. J. Am. Soc. Nephrol., 2006, 17(6), 1673-1687. https://doi.org/10.1681/ ASN.2006010088.

4. Seema,V. P. Int. J. Phytopharm., 2012, 2(1). https://www.researchgate.net/deref/http\% $3 \mathrm{~A} \% 2 \mathrm{~F} \% 2 \mathrm{Fdx}$.

5. Benn,T. M.; Westerhoff, P. Environ. Sci. Technol., 2008, 42, 4133-4139. https://doi. org/10.1021/es7032718.

6. Kumar, S. B. N.; Kumar, K. G.; Srinivasa, V.; Bilal, S. Int. J. Univ. Pharm. Life Sci., 2012, 2(2), 269280. https://doi.org/10.1155/ 2018/3068365.

7. Orisakeye, O. T.; Oladoye, S. O.; Peters, O. A. GSC Biol. Pharm. Sci., 2015. https://doi. org/10.30574/gscbps.2019.9.2.0184.

8. Vinod, V. T. P.; Saravanan, P.; Sreedhar, B.; Devi, D. K.; Sashidhar, R. B. Colloids Surf.
Biointerfaces., 2011, 83(2). https://doi. org/10.1515/eces-2016-0038.

9. Crozier, A.; Jaganath, I. B.; Clifford, M. N. Nat. Prod. Rep., 2009, 26, 1001-1043.https://doi. org/10.1039/b802662a.

10. Rajasekharreddy, P.; Rani, P.U.; Sreedhar, B. J. Nanopart. Res., 2010, 12(5),1711-1721. https://doi.org/10.1155/2013/278925.

11. Mahamadi, C.; Wunganayi, T. Med. Chem., 2018. https://doi.org/10.1080/23312009.201 8.1538547.

12. Huang, Y.; Chen, S.; Bing, X.; Gao, C.;Wang, T.;Yuan, R. Technol. Sci., 2011, 24, 291-297. https://doi.org/10.1002/pts.938.

13. Parez, A. C.; Correa, M. F.; Borges, S. R. Arch. Vet.Sci., 1999, 4(1), 111-112.https://dx.doi. org/10.5380/avs.v4i1.3792.

14. Agarwal, H.; Venkatkumar, S.; Rajeshkumar, S. J. Microbiol. Biotechnol. Food Sci., 2018, 7(4), 371-376. https://doi.org/10.15414/ jmbfs.2018.7.4.371-376.

15. Sohgaura, A. K.; Bigoniya, P.; Shrivastava, B. J. Pharm. Bioallied Sci., 2018, 10, 83-89. https://doi.org/10.4103/JPBS.JPBS_18_18. 